Der Bau der Erde und die Bewegungen ihrer Oberfläche: eine Einführung in die Grundfragen der allgemeinen Geologie. Von Prof. Dr. W. von Seidlitz. (Verständliche Wissenschaft, Band 17.) Pp. ix + 152. (Berlin: Julius Springer, 1932.) 4.80 gold marks.

Thrs little book is an excellent introduction to present-day geological thought. The classic question, first answered by Leonardo da Vinci, as to why sea shells are found in the rocks of high mountains, is here put again, and answered on modern lines.

The origin of rocks is lucidly explained on sound uniformitarian principles. It is worth noting, however, that the author directs attention to certain limitations in Aktualismus, as, for example, those due to the circumstance that the moist vegetationcovered Europe of to-day furnishes none too reliable a clue to the past.

The main part of the book is concerned of course with the movements to which the earth's crust has been subjected. The contrasts between the rapid, violent movements of the orogenic or mountainbuilding belts and the slow vertical movements of the more stable areas are developed. But, as we would expect from the anthor of "Diskordanz und Orogenese der Gebirge am Mittelmeer", we find the importance of the broad epirogenic movements consistently emphasised. The integration of minute movements leads to transgressions and regressions, and thus produces results of fundamental importance for earth history. One of the most interesting parts of an interesting book is that dealing with the detection of epirogenic movements in action at the present day. Further, positive uplift is considered to be the chief cause of mountains: "the mountains grow from the depths, and are still growing".

The book concludes with a table of geological formations, short bibliography, a glossary, and index.

A Textbook of Mineralogy: with an Extended Treatise on Crystallography and Physical Mineralogy. By Prof. E. S. Dana. Fourth edition, revised and enlarged by Prof. William E. Ford, Pp. xi +851 . (New York: John Wiley and Sons, Inc.; London: Chapman and Hall, Ltd., 1932.) 34s. net.

CERTAIN additions and much revision, as compared with the third edition of 1922 , have been made in this new edition of E. S. Dana's well-known textbook. The chief additions are two. The crystallography section now includes a short account of crystal structure, as revealed by X-ray analysis, which provides a good introduction to an increasingly important branch of mineralogy. A section entitled "Origin, Mode of Occurrence and Association of Minerals" is new to this book, though much of it has appeared in Dana's "Manual of Mineralogy". This section consists of less than twenty pages, so that only a very inadequate summary of mineral paragenesis is presented.
The descriptive part of the book has been revised, the most recent data incorporated, and accounts of more than two hundred new minerals added. Descriptions, short or long, of all known minerals are given. It has been Prof. Ford's aim to give the important facts of mineralogy as known "on January 1, 1932". In this, so far as a work of this kind ean be tested, he seems to have succeeded.

\section{Mathematical and Physical Sciences}

British Association for the Advancement of Science. Mathematical Tables. Vol. 1: Circular and Hyperbolic Functions, Exponential Sine and Cosine Integrals, Factorial (Gamma) and Derived Functions, Integrals of Probability Integral. Prepared by the Committee for the Calculation of Mathematical Tables. Pp. xxxvi $+72.10 s$. Vol. 2: Emden Functions: Being Solutions of Emden's Equation, together with Certain Assoc. iated Functions. Prepared by the Commission for the Constitution of the Stars of the International Astronomical Union and the British Association Committee for the Calculation of Mathematical Tables. Pp. viii +34 . 7s.6d. (London: British Association, 1931 and 1932.)

From 1873 onwards, at irregular intervals, the British Association has published in its annual report various mathematical tables. Unfortunately, these were generally compiled for special purposes, and when regarded as a whole were not well suited for general use. To remedy this defect a committee undertook the heavy task of filling the gaps and (a point altogether neglected in the original form) making them suitable for interpolation. The first volume, begun by R. A. Fisher and completed by J. Henderson, with the assistance of J. R. Airey, L. J. Comrie, A. T. Doodson, A. Lodge, J. Wishart, and others, contains sixteen tables. Some of these are new, and two of them (dealing with tetragamma and pentagamma functions) are the only tables of these functions in existence. The degree of accuracy is high, extending (except in the last) from ten to fifteen decimal places. There is an elaborate introduction filling thirty pages, beginning with interpolation, using Everett's formula and central differences of even orders, for which these tables are specially suitable. After a brief treatment of the better-known functions, the introduction concludes with an extensive account of the properties of certain probability repeated integrals (really Hermite functions) and their applications to statistics.

The second volume is entirely devoted to solutions of Emden's differential equation, which is fundamental in modern theories of the internal structure of the stars, and to certain auxiliary functions. The work, undertaken at the request of Sir Arthur Eddington, was carried out by J. R. Airey, J. C. P. Miller, and D. H. Sadler.

H.T.H.P. 